\title{
DETERMINATION OF SEX FROM VARIOUS MEASUREMENTS OF MANDIBULAR RAMUS AND MENTAL FORAMEN PARAMETERS USING DIGITAL PANORAMIC IMAGING IN A SAMPLE OF SOHAG GOVERNORATE POPULATION
}

Reda M. Elsayed, Maha A. Hilal, Hend M. Mahmoud, Ahmed M. Said. Forensic Medicine \&Clinical Toxicology Department, Faculty of Medicine, Sohag

Corresponding author: Reda M. Elsayed University, Sohag, Egypt.

Forensic Medicine \&Clinical Toxicology Department, Faculty of Medicine, Sohag University, Sohag, Egypt.

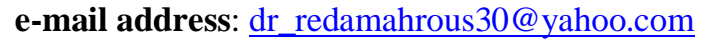
mob.: 01010870865

Date of submission: 24 September 2020

Revised at: 2 December 2020

Accepted at: 8 December 2020

\begin{abstract}
Determination of human skeletal remnants is a vital step during mass disasters, from decayed and damaged dead bodies. In forensic investigations and medicolegal cases, identification of sex is an essential aspect, followed by age determination. Skeletal components most often investigated for gender determination are pelvis and skull, with the mandible being a practical element to analyze sexual dimorphism in fragmented bones. The mandible is the largest, strongest, and movable part of the skull. Objectives: The present study was designed to compare mandibular ramus measurements and mental foramen parameters on both sides to determine sex through digital panoramic radiography. Methodology: The present study included 150 adult patients, 75 were males, and 75 were female who performed panoramic x-ray. Their ages ranged from 25 to 50 years. Results: The present study revealed no significant difference between right and left sides regarding all measured mandibular and mental foramen parameters in males and females. A significant statistical increase in all measured mandibular and mental mean values was no significant statistical difference between males and females. The mean values of right and left Condylar Ramus height and distance from the superior margin of the mental foramen to the mandible (SM-IB) inferior margin were the correct predictors of both genders.
\end{abstract}

Keywords: Mandibular ramus measurements, mental foramen parameters, digital panoramic radiography, sexual dimorphism.

\section{INTRODUCTION}

Identification of human skeletal remnants from putrefied and destroyed dead bodies during mass disasters represents an important step. In medicolegal cases and forensic investigations, the determination of sex represents an essential step, followed by age determination (Bhagwatkar et al., 2016).

Sex identification, age, and ethnicity play essential roles in identifying an unknown individual. Sex identification specifically remains a crucial aspect of identifying unknown human remains in forensic medicine, mainly when it is impossible to obtain whole skeletons or remains for analysis (Kiran et al., 2014).

The most common investigated skeletal components for sex determination are pelvic bones and the skull with the mandible. They are a practical part of analyzing sexual dimorphism in an incomplete skeleton (Jambunath et al., 2016). Mandible represents the biggest, strenuous, and movable part of the skull (Kumar and Lokanadham, 2013).

The difference between males and females in the development of mastication muscles in size, power, and angulation can be one of the causes of mandibular 
dimorphism in males and females (Franklin et al., 2008).

Most of the studies were conducted using the manual method of metric analysis on the dry bone, which is timeconsuming, and the technique is prone to error. As panoramic radiography is a part of the routine radiographic examination for a large population segment for the diagnosis of many oral diseases, the emergence of digitization has image accuracy and simplified image storing and sharing. The advent of user-friendly software has made metric analysis easy and less time consuming (Tsorovas and Karsten, 2010).

The most important advantages of this specialized radiography include broad coverage, a small dose of radiation, easy examination, and a short time is required to make images and perfect for the different measurements on mandibles (Kartheeki et al., 2017).

\section{AIM OF THE WORK}

The present work aims to assess and compare various mandibular ramus and mental foramen parameters in sex determination using digital panoramic imaging in a Sohag governorate population.

\section{SUBJECTS AND METHODS}

1- Subjects:

The present study was carried out on 150 subjects (75 females and 75 males) who performed panoramic $\mathrm{x}$-ray in a private dental conducted radiology center in Sohag on their teeth, upper and lower jaws for various reasons. However, their panoramic $\mathrm{X}$-rays did not show any pathological findings. Their ages ranged from 25 to 50 years. The age and sex of the patients were recorded.

Exclusion criteria:

Subjects excluded from the study those with a history of:

1-Trauma of the mandible.

2- Fracture or malunion of the mandible.
3- hereditary facial asymmetry (Congenital anomalies in the mandible).

4-Any mandibular pathology.

5. Completely edentulous mandible.

6-Mandibular surgical interference. (facial interventions in the lower jaw).

The study was approved by scientific, ethical committees of Sohag Faculty of Medicine, and informed written consent obtained from all subjects.

\section{2-Apparatus: -}

All the digital panoramic radiograph images were obtained from the patients using a Promax unit (Planmeca Oy, Helsinki, Finland) at a private dental radiology center at Sohag. The formatting and enhancement of images obtained from this high-quality apparatus provide perfect and reproducible measurements.

\section{3-Methods: -}

Ideal orthopantomographs of completely dentate patients were performed with right head alignment, contrast, and visible mandibular borders, condyles, rami, and mental foramina were selected for the study. After imaging, mandibular ramus measurements and mental foramen parameters on both sides were evaluated and compared to determine the sex using Romexis 4.2.r software, built-in software with the apparatus by using the mouse-driven method. It is conducted by moving the mouse and drawing lines using specific points on the digital panoramic radiograph.

(A) Ramus measures: (Jambunath et al., 2016).

Maximum ramus breadth (Max.R.Br.): The distance between the most anterior point on the mandibular ramus and a line connecting the most posterior point on the condyle and the angle of the jaw.

- Minimum ramus breadth (Min.R.Br.): Smallest anterior-posterior diameter of the ramus.

- Condylar ramus height (Condylar.R. $\mathrm{Ht}$ ): Height of the mandibular ramus from the highest point on the mandibular 
condyle to the tubercle, or most protruding portion of the inferior border of the ramus.

- Coronoid ramus height (Coronoid.R.Ht): Projective distance between the highest point of coroniod to the most protruding portion of the ramus's inferior border.

(B) Mental foramen parameters:( Vijay and Jigna, 2018)

$>$ Distance from superior margin of mental foramen to alveolar crest of the mandible (SM-AC).

Distance from the superior margin of the mental foramen to the mandible's inferior margin (SM-IB).

Distance from the inferior margin of the mental foramen to the mandible's inferior margin (IM-IB).

Statistical analysis: -

Data were analyzed using the SPSS computer program version16.0. Quantitative data were expressed as means \pm standard deviation in tables. The percentage of correct prediction of sex is calculated for both males and females using the benchmark scale that Landis and Koch proposing the extent of agreement can be qualified depending on the magnitude of kappa (Landis and Koch, 1977).

\section{RESULTS}

(A) Ramus measurements: -

No significant difference was detected between the mean values for both left and right Max.R.Br., and the mean values for the left and right Min.R.Br in the male participants of this study as p-value was (0.96 and 0.31 respectively) as shown in (table $1 \&$ fig. 1 ).

No significant difference was detected between the mean values for the left and right Max.R.Br and the mean values for the left and right Min.R.Br. in the female participants of this study as p-value was $(0$. 908 and 0.954 respectively) as shown in (table $1 \&$ fig. 2).

The mean values of the right Max.R. $\mathrm{Br}$ in males were higher (39.37) as compared with females (35.20), where P- value was (0.021). However, no statistical difference was found between the means of the right Min.R.Br. between males and females (28.18 and 26.43 respectively) where P-value was (0.118) as shown in (table 2).

A significant statistical increase in the mean values of the left Max.R. Br in males (39.36) was found as compared with females (35.17) where P-value was (0.011). However, no significant difference was detected between the mean values for the left Min.R. Br between males and females (28.27 and 26.41 respectively) where P-value was (0.120) as shown in (table 2).

Among male participants of the present study, no statistical difference was detected between the mean values of the left and right Condylar.R. Ht (67.78 and 67.77 respectively) where p-value was (0.979). Also, it was no statistical difference detected between the mean values of the left and right Coronoid.R.Ht (58.91 and 58.87 respectively where the Pvalue was (0.932), as shown in (table $3 \&$ figure 3$)$.

Among female participants of the present study, no significant difference was found between the mean values of the left and right Condylar.R. Ht (58.77 and 58.76, respectively) where the $\mathrm{P}$-value was (0.789). Also, no significant statistical difference was detected between the mean values of the left and right Coronoid.R.Ht (53.74 and 53.73 respectively) where pvalue was (0.977), as shown in (table $3 \&$ figure 4).

Among male and female participants, a significant statistical increase in the mean values of the right Condylar.R.Ht was found in males (67.78) as compared with females (58.77) where P-value was (0.001). Also, a significant statistical increase in the mean values of the right Coronoid.R.Ht was found in males (58.91) as compared with females (53.74), where P-value was (0.001) as shown in (table 4).

Among male and female participants, there was a highly significant statistical 
increase in the mean values of the left Condylar.R.Ht in males (67.77) as compared to females (58.76) where Pvalue was (0.001). Also, there was a highly significant statistical increase in the mean values of the left Coronoid.R.Ht in males (58.87) as compared with females (53.73), where the P-value was (0.001) as shown in (table 4).

(B) Mental foramen parameters:-

Among male participants of the present study, there was no statistical difference between the mean values of the left and right SM-AC (15.26 and 15.88, respectively), where the $\mathrm{P}$-value was (0.962). There was no statistical difference between the mean values of the left and right SM-IB (15.20 and 15.39, respectively) where the P-value was (0.692). Also, there was no statistical difference between the mean values of the left and right IM-IB (11.50 and 11.60 respectively) where the P-value was (0.936) as shown in (table 5 \&figure5)

Among female participants of the present study, no significant statistical difference was found between the mean values of the right and left SM-AC (14.40 and 14.35 , respectively) where P-value was (0.808). No significant difference was detected between the mean values of the right and left SM-IB (13.70 and 13.63, respectively), where P-value was (0.818). Also, no significant statistical difference was found between the mean values of the right and left IM-IB (10.38 and 10.33, respectively) where P-value was (0.872), as shown in (table $5 \&$ figure 6 ).

Among male and female participants, a significant statistical increase in the mean values of the right SM-AC was found in males (15.26) as compared with females (14.40), where P-value was (0.030). A high significant statistical increase was found in the mean values of the right SM-IB in males (15.20) as compared with females (13.70), where P-value was (0.001). Also, a highly significant statistical increase was found in the mean values of the right IMIB in males (11.50) as compared with females (10.38) where P-value was (0.001), as shown in (table 6).

Among male and female participants, a significant statistical increase in the mean values of the left SM-AC was found in males (15.88) as compared with females (14.35) where P-value was (0.032) also a highly significant statistical increase in the mean values of the left SM-IB was found in males (15.39) as compared with females (13.63) where P-value was (0.001). Also, a highly significant statistical increase was found in the mean values of the left IM-IB in males (11.60) as compared with females (10.33), where P-value was (0.001), as shown in (table 6).

$>$ The percentage of correct prediction of sex:-

The percentage of correct prediction of sex is calculated for both males and females using the benchmark scale that Landis and Koch (1977) proposing the degree of agreement can be qualified as "Poor" $(\mathrm{k}<0)$, "Slight" $(\mathrm{k}=0-0.20)$, "Fair" ( $\mathrm{k}=0.21-0.40), \quad$ "Moderate" $(\mathrm{k}=0.41-0.60)$, "Substantial" (k=0.61-0.80), and "Almost perfect" $(\mathrm{k}=0.81-1.00)$ depending on the magnitude of kappa.

- Mandibular ramus measurements in the prediction of sex:-

For the right Max.R.Br, the kappa coefficient was $(\mathrm{k}=0.46, \quad \mathrm{p}<0.001)$, indicating a moderate agreement degree. $68 \%$ of males \& $74 \%$ of females were correctly predicted using the right Max.R.Br. While the right Min.R.Br, the kappa coefficient was $(\mathrm{k}=0.11, \mathrm{P}<0.001)$, indicating a slight agreement degree. 55\% of males \& $59 \%$ of females were correctly predicted using right Min.R.Br, as shown in (table 7).

Regarding the right Condylar.R.Ht, the kappa coefficient was $(\mathrm{k}=0.95, \mathrm{P}<0.001)$, indicating a perfect agreement degree. $97 \%$ of males \& $100 \%$ of females were correctly predicted using the right Condylar.R.Ht. While the right Coronoid.R.Ht were as follows: the kappa coefficient was $(\mathrm{k}=0.80, \quad \mathrm{P}<0.001)$, indicating a substantial agreement degree. 
$90 \%$ of males \& $95 \%$ of females were correctly predicted using right Coronoid.R.Ht as shown in (table 7).

For the left Max.R.Br, the kappa coefficient was $(k=0.47, \quad p<0.001)$, indicating a moderate agreement degree. $78 \%$ of males \& $63 \%$ of females were correctly predicted using left Max.R.Br. For the left Min.R.Br, the kappa coefficient was $(\mathrm{k}=0.10, \mathrm{P}<0.001)$, indicating a slight agreement degree. $60 \%$ of males \& $52 \%$ of females were correctly predicted using left Min.R.Br, as shown in (table 7).

Regarding the left Condylar.R.Ht, the kappa coefficient was $(\mathrm{k}=0.96, \mathrm{P}<0.001)$, indicating a perfect agreement degree. $97 \%$ of males \& $100 \%$ of females were correctly predicted using left Condylar.R.Ht. The left Coronoid.R.Ht were as follows: the kappa coefficient was ( $\mathrm{k}=0.73, \mathrm{P}<0.001)$, indicating a substantial agreement degree. $86 \%$ of males \& $92 \%$ of females were correctly predicted using left Coronoid.R.Ht as shown in (table 7)

- Mental foramen parameters in the prediction of sex:-

The right SM-AC results in the kappa coefficient was $(\mathrm{k}=0.52, \mathrm{P}<0.001)$, indicating a moderate agreement degree.
By using the right SM-AC, $79 \%$ of males \& $85 \%$ of females were correctly predicted. In comparison, the right SM-IB the kappa coefficient was $(\mathrm{k}=0.89, \mathrm{P}$ $<0.001$ ), indicating a perfect agreement degree. By using the right SM-IB, 96\% of males \& $100 \%$ of females were correctly predicted. The right IM-IB was as follows: the kappa coefficient was $(\mathrm{k}=0.75, \mathrm{P}$ $<0.001$ ), indicating a substantial agreement degree. Using the right Coronoid.R.Ht, $89 \%$ of males \& $90 \%$ of females were correctly predicted, as shown in (table 8).

In the left SM-AC results, the kappa coefficient was $(\mathrm{k}=0.56, \mathrm{P}<0.001)$, indicating a moderate agreement degree. $81 \%$ of males \& $85 \%$ of females were correctly predicted using left SM-AC. While the left SM-IB, the kappa coefficient was $(k=0.90, \quad P<0.001)$, indicating a perfect agreement degree. $100 \%$ of males \& $93 \%$ of females were correctly predicted using left SM-IB. The left IM-IB was as follows: the kappa coefficient was $(\mathrm{k}=0.78$, $\mathrm{P}<0.001)$, indicating a substantial agreement degree. $95 \%$ of males \& $83 \%$ of females were correctly predicted using left Coronoid.R.Ht as shown in (table 8).

Table (1): Comparison between the mean values and SD of right and left Max.R.Br and Min. R.Br in males and females $(\mathrm{N}=150)$.

\begin{tabular}{|c|c|c|c|c|}
\hline Subjects & \multicolumn{2}{|c|}{ Males } & \multicolumn{2}{c|}{ Females } \\
\hline \multirow{2}{*}{ Items } & Max.R.Br & Min.R.Br & Max.R.Br & Min.R.Br \\
\cline { 2 - 5 } & Mean $\pm * *$ SD & Mean \pm SD & Mean \pm SD & Mean \pm SD \\
\hline Right & $39.37 \pm 2.34$ & $28.18 \pm 1.96$ & $35.20 \pm 1.92$ & $26.43 \pm 1.69$ \\
\hline Left & $39.36 \pm 2.33$ & $31.27 \pm 2.67$ & $35.17 \pm 1.89$ & $26.41 \pm 1.66$ \\
\hline *P-value by t-test & 0.964 & 0.318 & 0.908 & 0.954 \\
\hline * Significant statistical difference at $\mathrm{P}<0.05 \quad * * S D=$ standard deviation
\end{tabular}




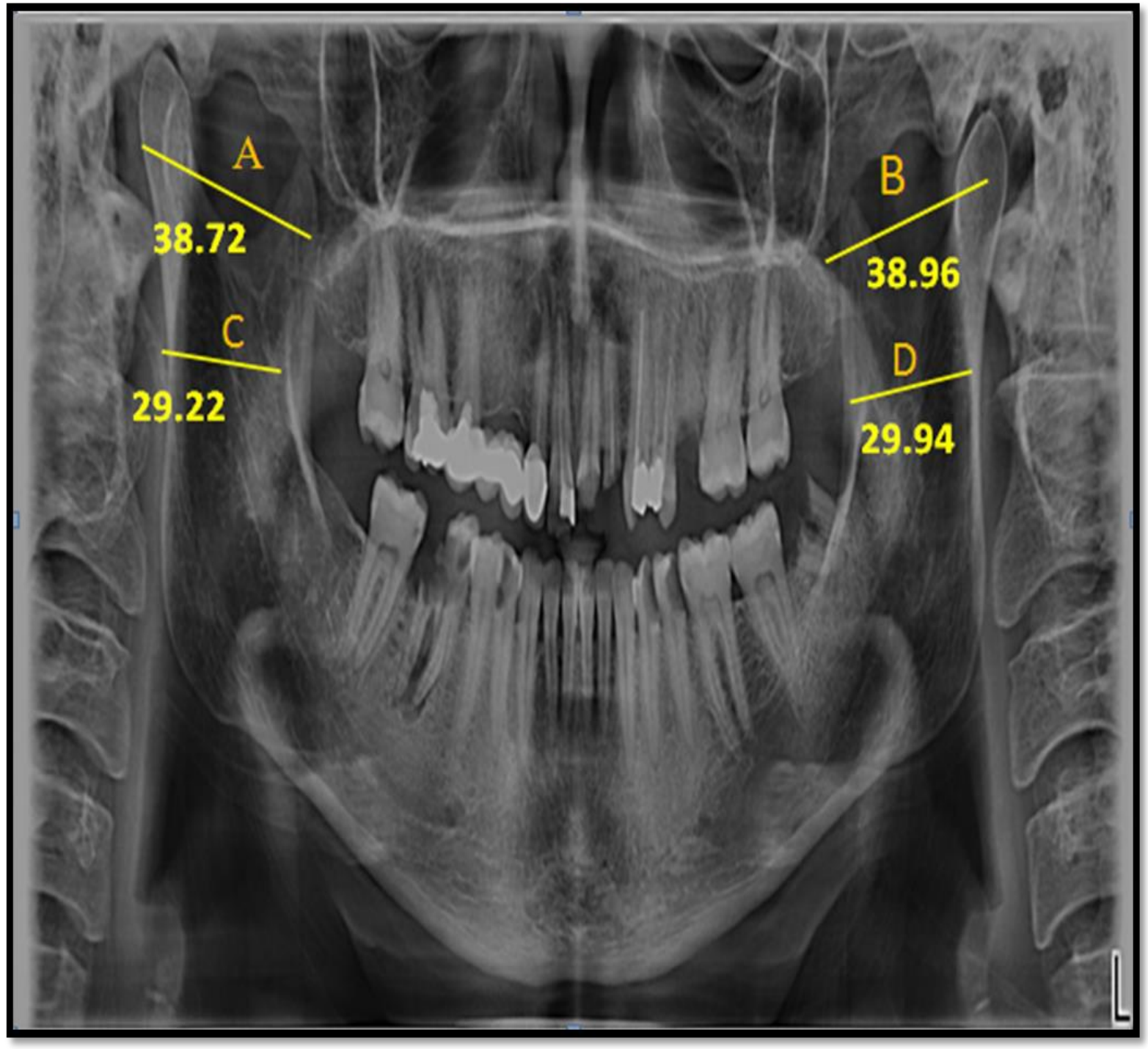

Figure (1): Panoramic radiograph showing Max.R.Br and Min.R.Br on both right and left sides in one of the males participants: (A) right Max.R.Br; (B) left Max.R.Br; (C) right Min.R.Br; (D)left Min.R.Br.

Table (2): Comparison between males and females in the mean values and SD of right and left Max.R. Br and Min.R.Br $(\mathrm{N}=150)$.

\begin{tabular}{|l|l|c|c|c|}
\hline \multirow{2}{*}{ Items } & Right Max.R.Br & Right Min.R.Br & Left Max.R.Br & Left Min.R.Br \\
\cline { 2 - 5 } & Mean \pm SD & Mean \pm SD & Mean \pm SD & Mean \pm SD \\
\hline Males & $39.37 \pm 2.34$ & $28.18 \pm 1.96$ & $39.36 \pm 2.33$ & $28.27 \pm 2.67$ \\
\hline Females & $35.20 \pm 1.92$ & $26.43 \pm 1.69$ & $35.17 \pm 1.89$ & $26.41 \pm 1.66$ \\
\hline P-value by t-test & $0.021 *$ & 0.118 & $0.011 *$ & 0.120 \\
\hline \multicolumn{4}{|c|}{$*$ Significant statistical difference at P<0.05 **SD=standard deviation }
\end{tabular}




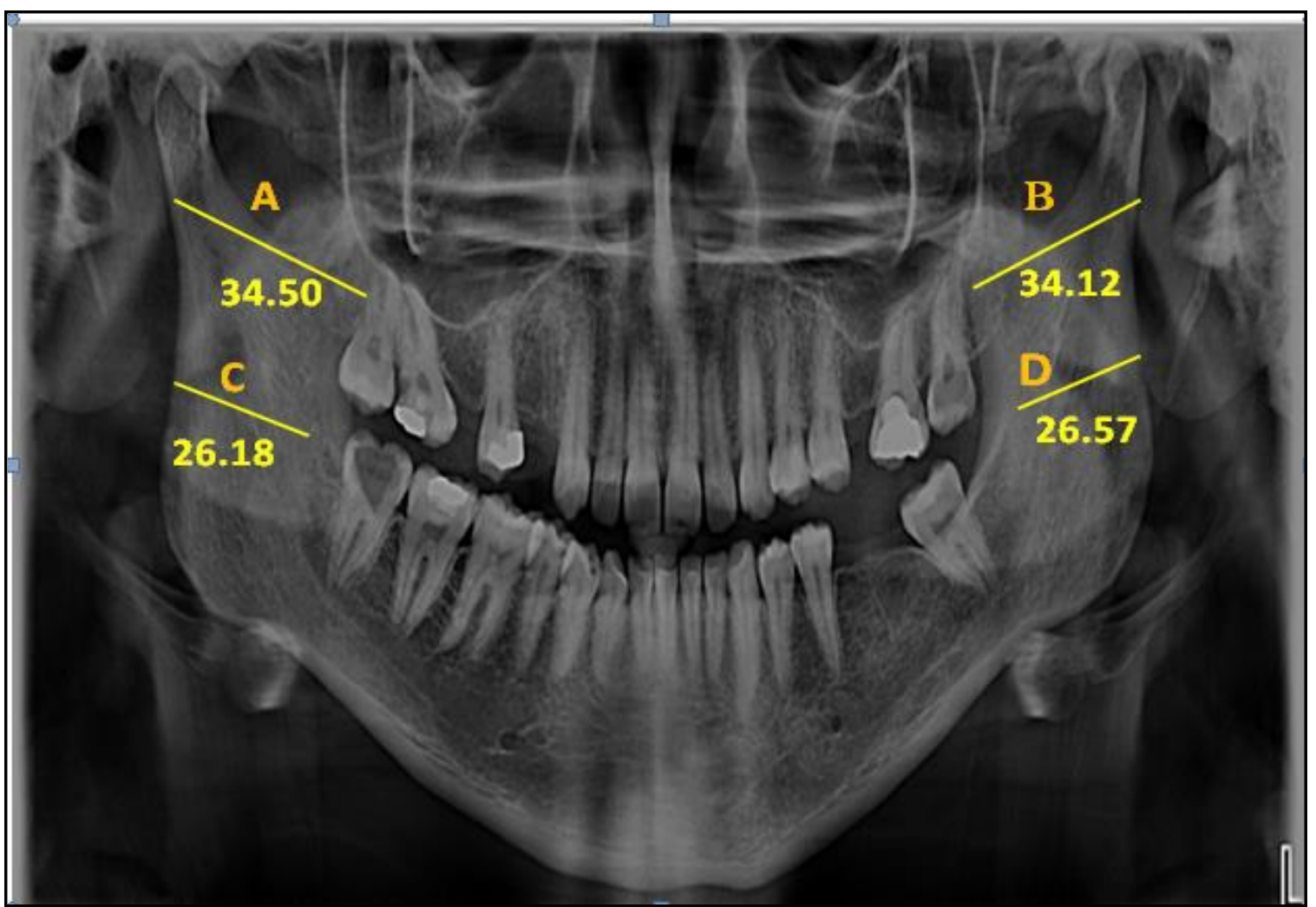

Figure (2): Panoramic radiograph showing Max.R.Br and Min.R.Br on both right and left sides in one of the females participants: (A) right Max.R.Br; (B) left Max.R.Br; (C) right Min.R.Br; (D)left Min.R.Br.

Table (3): Comparison between the mean values and SD of right and left of Condylar.R.Ht and Coronoid.R.Ht in males and females $(\mathrm{N}=150)$.

\begin{tabular}{|l|c|c|c|c|}
\hline \multicolumn{1}{|c|}{ Subjects } & \multicolumn{2}{c|}{ Males } & \multicolumn{2}{c|}{ Females } \\
\hline \multirow{2}{*}{ Items } & Condylar.R.Ht & Coronoid.R.Ht & Condylar.R.Ht & Coronoid.R.Ht \\
\cline { 2 - 5 } & Mean \pm SD & Mean \pm SD & Mean \pm SD & Mean \pm SD \\
\hline Right & $67.78 \pm 2.73$ & $58.91 \pm 2.99$ & $58.77 \pm 2.38$ & $53.74 \pm 2.63$ \\
\hline Left & $67.77 \pm 2.77$ & $58.87 \pm 2.93$ & $58.76 \pm 2.38$ & $53.73 \pm 2.67$ \\
\hline P-value by t-test & 0.979 & 0.932 & 0.789 & 0.977 \\
\hline \multicolumn{2}{r}{$*$ Significant statistical difference at P<0.05 } & $* *$ SD=standard deviation
\end{tabular}




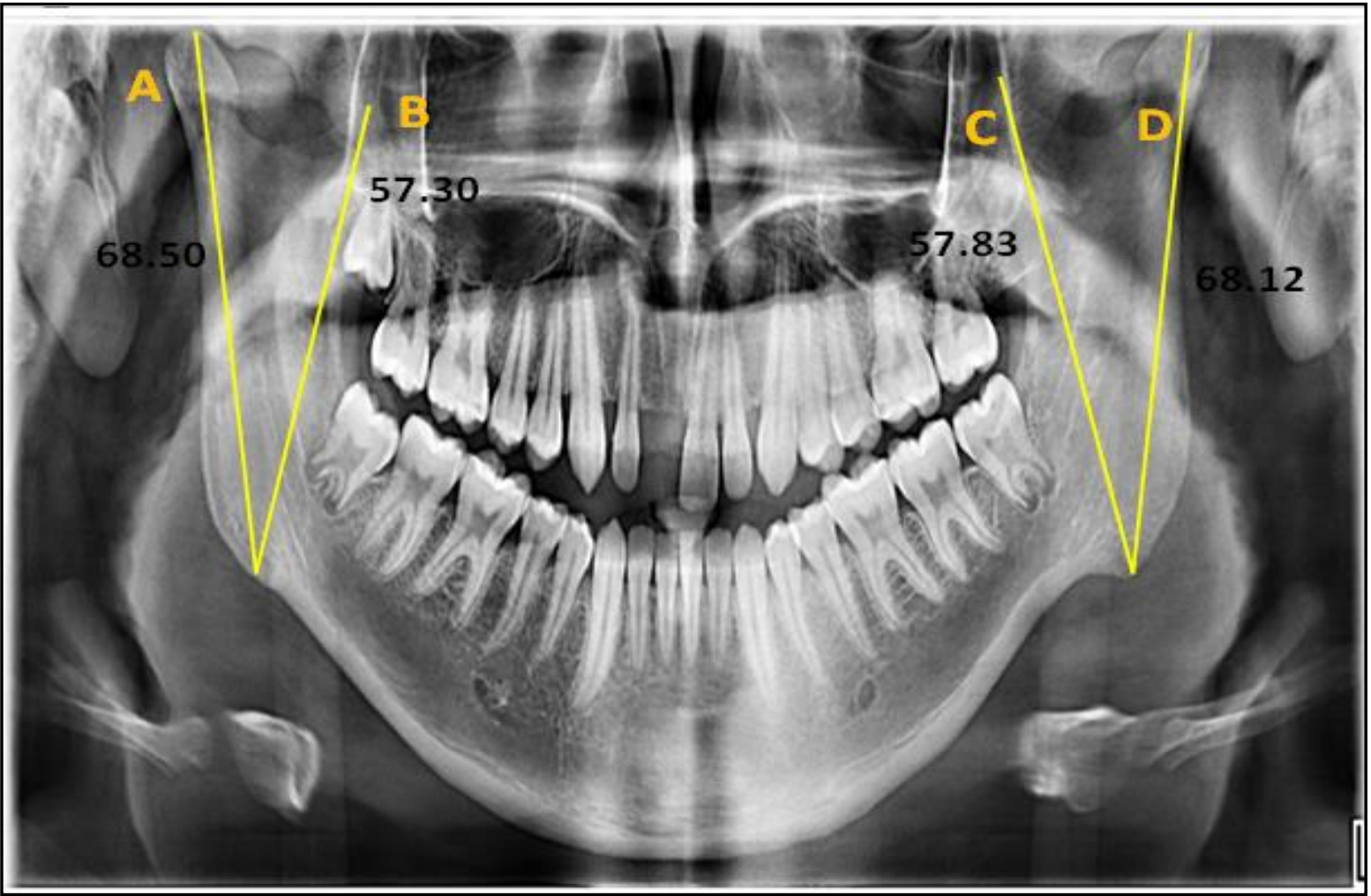

Figure (3): Panoramic radiograph showing Condylar.R.Ht and Coronoid.R.Ht on both right and left sides in one of the males participants: (A)right Condylar.R.Ht; (B) right Coronoid.R.Ht; (C) left Coronoid.R.Ht; (D)left Condylar.R.Ht

Table (4): Comparison between males and females in the mean values and SD of right and left Condylar.R.Ht and Coronoid.R.Ht $(\mathrm{N}=150)$.

\begin{tabular}{|c|c|c|c|c|}
\hline \multirow{2}{*}{ Items } & $\begin{array}{c}\text { Right } \\
\text { Condylar.R.Ht }\end{array}$ & $\begin{array}{c}\text { Right } \\
\text { Coronoid.R.Ht }\end{array}$ & $\begin{array}{c}\text { Left } \\
\text { Condylar.R.Ht }\end{array}$ & $\begin{array}{c}\text { Left } \\
\text { Coronoid.R.Ht }\end{array}$ \\
\cline { 2 - 5 } & Mean \pm SD & Mean \pm SD & Mean \pm SD & Mean \pm SD \\
\hline Males & $67.78 \pm 2.73$ & $58.91 \pm 2.99$ & $67.77 \pm 2.77$ & $58.87 \pm 2.93$ \\
\hline Females & $58.77 \pm 2.38$ & $53.74 \pm 2.63$ & $58.76 \pm 2.38$ & $53.73 \pm 2.67$ \\
\hline $\begin{array}{c}\text { P-value by } \\
\text { t-test }\end{array}$ & $0.001^{*}$ & $0.001^{*}$ & $0.001^{*}$ & $0.001^{*}$ \\
\hline
\end{tabular}

* Significant statistical difference at $\mathrm{P}<0.05 * * \mathrm{SD}=$ standard deviation 


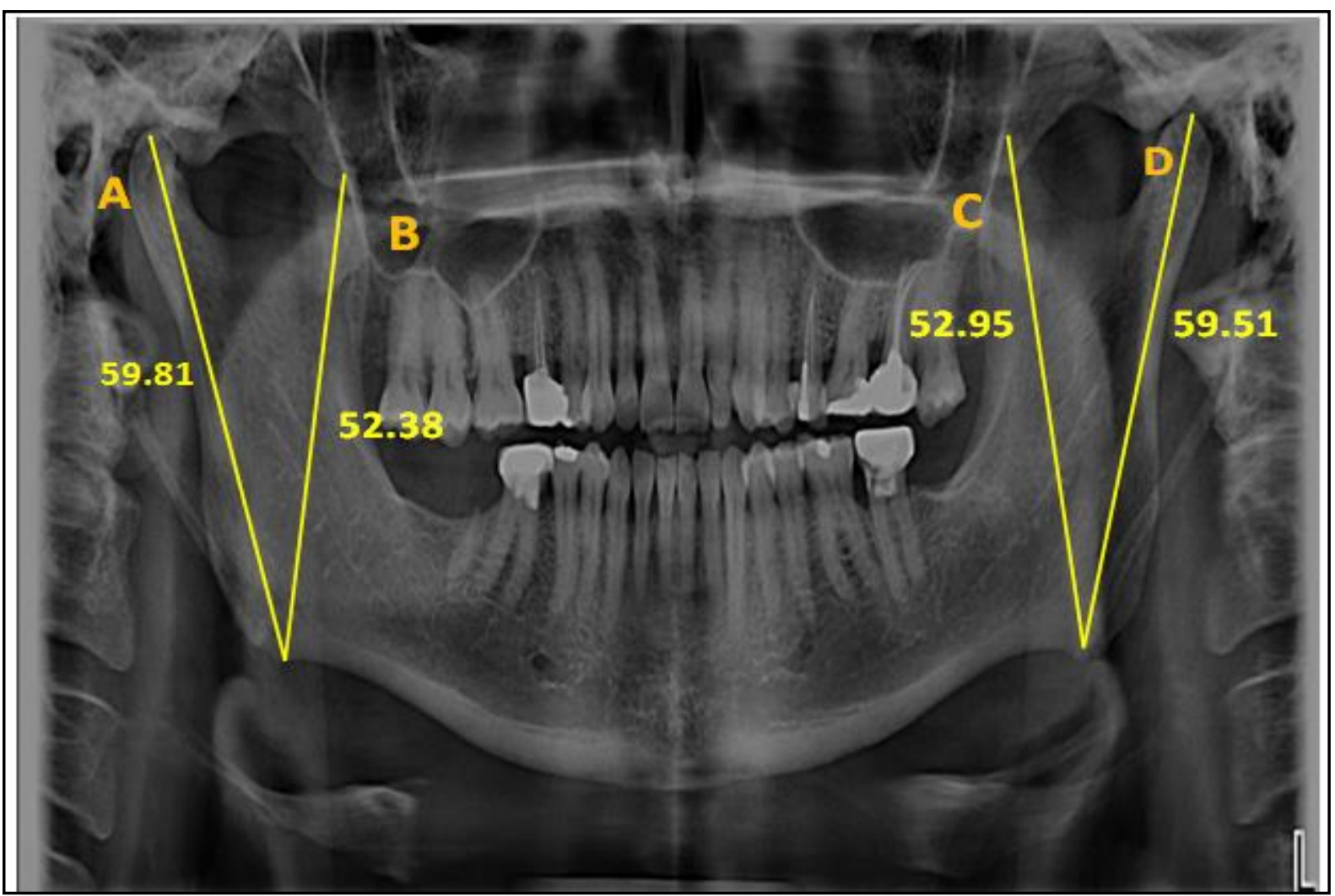

Figure (4): Panoramic radiograph showing Condylar.R. Ht and Coronoid.R. Ht on both right and left sides in one of the females participants: (A)right Condylar.R. Ht; (B) right Coronoid.R.Ht; (C) left Coronoid.R.Ht; (D)left Condylar.R.Ht.

Table (5): Comparison between the mean values and SD of right and left sides mental foramen parameters in males and females $(\mathrm{N}=150)$.

\begin{tabular}{|c|c|c|c|c|c|c|}
\hline Subjects & \multicolumn{3}{|c|}{ Males } & \multicolumn{3}{c|}{ Females } \\
\hline \multirow{2}{*}{ Items } & (SM-AC) & $($ SM-IB) & (IM-IB) & (SM-AC) & (SM-IB) & (IM-IB) \\
& & & & & & \\
\cline { 2 - 7 } & Mean \pm & Mean \pm & Mean \pm & Mean \pm SD & Mean \pm & Mean \pm \\
& SD & SD & SD & & SD & SD \\
\hline Right & $15.26 \pm$ & $15.20 \pm$ & $11.50 \pm$ & $14.40 \pm$ & $13.70 \pm$ & $10.38 \pm$ \\
& 2.08 & 1.28 & 1.34 & 1.20 & 1.68 & 2.02 \\
\hline Left & $15.88 \pm$ & $15.39 \pm$ & $11.60 \pm$ & $14.35 \pm$ & $13.63 \pm$ & $10.33 \pm$ \\
& 2.01 & 1.27 & 1.41 & 1.27 & 1.69 & 2.01 \\
\hline P-value by t-test & 0.962 & 0.692 & 0.936 & 0.808 & 0.818 & 0.872 \\
\hline
\end{tabular}




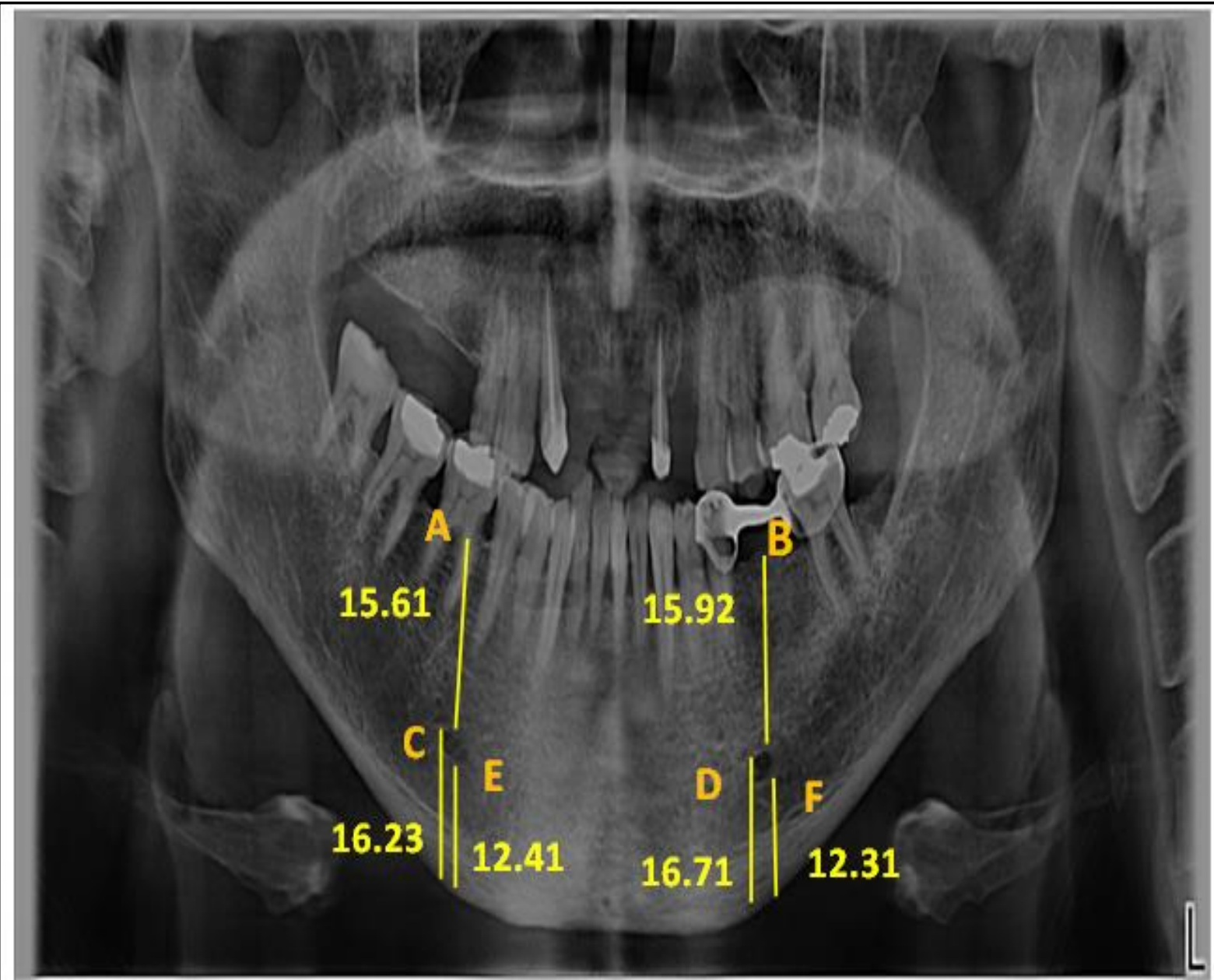

Figure (5): Panoramic radiograph showing mental foramen parameters on both right and left sides in one of the male's participants: (A) right (SM-AC); (B) left (SM-AC); (C) right (SM-IB); (D) left (SM-IB); (E) right (IM-IB); (F) left (IM-IB).

Table (6): Comparison between males and females in the mean values and SD of right and left mental foramen parameters $(\mathrm{N}=150)$.

\begin{tabular}{|c|c|c|c|c|c|c|}
\hline \multirow{2}{*}{ Items } & $\begin{array}{c}\text { Right } \\
(\text { SM-AC) }\end{array}$ & $\begin{array}{c}\text { Right } \\
\text { (SM-IB) }\end{array}$ & $\begin{array}{c}\text { Right } \\
(\text { IM-IB) }\end{array}$ & $\begin{array}{c}\text { Left } \\
\text { (SM-AC) }\end{array}$ & $\begin{array}{c}\text { Left } \\
(\text { SM-IB) }\end{array}$ & $\begin{array}{c}\text { Left } \\
(\text { IM-IB) }\end{array}$ \\
\cline { 2 - 7 } & Mean \pm & Mean \pm & Mean \pm & Mean \pm & Mean \pm & Mean \pm \\
SD & SD & SD & SD & SD & SD \\
\hline Males & $15.26 \pm$ & $15.20 \pm$ & $11.50 \pm$ & $15.88 \pm$ & $15.39 \pm$ & $11.60 \pm$ \\
& 2.08 & 1.28 & 1.34 & 2.01 & 1.27 & 1.41 \\
\hline Females & $14.40 \pm$ & $13.70 \pm$ & $10.38 \pm$ & $14.35 \pm$ & 13.63 & $10.33 \pm$ \\
& 1.20 & 1.68 & 2.02 & 1.27 & \pm 1.69 & 2.01 \\
\hline $\begin{array}{c}\text { P-value by t- } \\
\text { test }\end{array}$ & $0.030^{*}$ & $0.001^{*}$ & $0.001^{*}$ & $0.032^{*}$ & $0.001^{*}$ & $0.001^{*}$ \\
\hline
\end{tabular}

* Significant statistical difference at $\mathbf{P}<0.05 * * \mathrm{SD}=$ standard deviation 


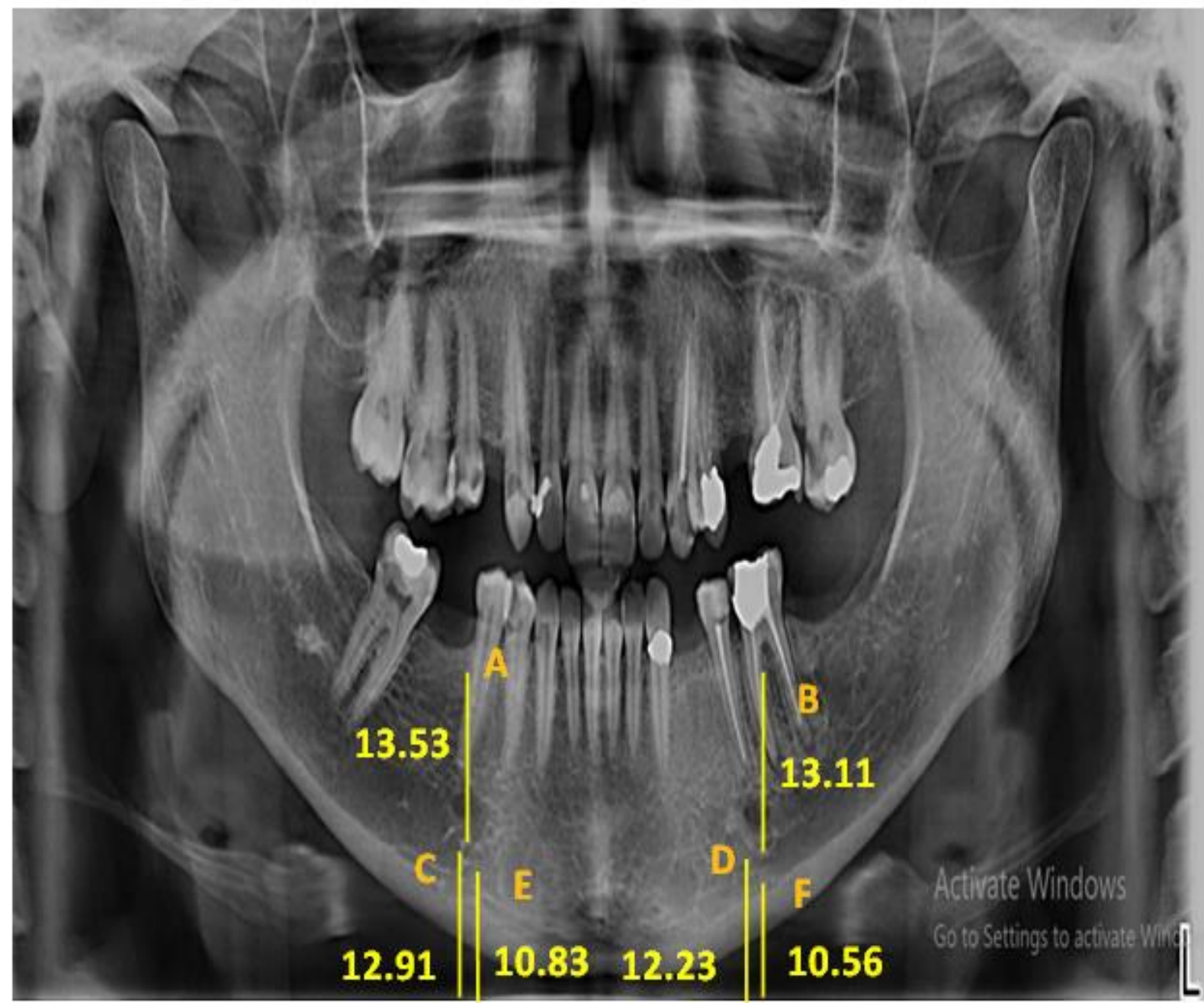

Figure (6): Panoramic radiograph showig mental foramen parameters on both right and left sides in one of the females participants: (A) right (SM-AC); (B) left (SM-AC); (C) right (SM-IB); (D) left (SM-IB); (E) right (IM-IB); (F)left (IM-IB).

Table (7): The degree of predictability of the mandibular ramus measurements on both right and left sides regarding sex determination.

\begin{tabular}{|c|c|c|c|c|}
\hline \multirow{2}{*}{ Measure } & \multicolumn{2}{|c|}{$\begin{array}{c}\text { Percentage of Correct } \\
\text { Predictions }\end{array}$} & \multirow{2}{*}{ Kappa (K) } & \multirow{2}{*}{ P-value } \\
\cline { 2 - 3 } & Male & Female & & \\
\hline Right Max.R.Br & $68 \%$ & $74 \%$ & 0.46 & $<0.001$ \\
\hline Right Min.R.Br & $55 \%$ & $59 \%$ & 0.11 & $<0.001$ \\
\hline Right Condylar.R.Ht & $97 \%$ & $100 \%$ & 0.95 & $<0.001$ \\
\hline Right Coronoid.R.Ht & $90 \%$ & $95 \%$ & 0.80 & $<0.001$ \\
\hline Left Max.R.Br & $78 \%$ & $63 \%$ & 0.47 & $<0.001$ \\
\hline Left Min.R.Br & $60 \%$ & $52 \%$ & 0.10 & $<0.001$ \\
\hline Left Condylar.R.Ht & $97 \%$ & $100 \%$ & 0.96 & $<0.001$ \\
\hline Left Coronoid.R.Ht & $86 \%$ & $92 \%$ & 0.73 & $<0.001$ \\
\hline
\end{tabular}


Table (8): The degree of predictability of the mental foramen parameters on both right and left sides regarding sex determination.

\begin{tabular}{|c|c|c|c|c|}
\hline \multirow{2}{*}{ Measure } & \multicolumn{2}{|c|}{$\begin{array}{c}\text { Percentage of Correct } \\
\text { Predictions }\end{array}$} & \multirow{2}{*}{ Kappa (K) } & \multirow{2}{*}{ P-value } \\
\cline { 2 - 3 } & Male & Female & & \\
\hline Right SM-AC & $79 \%$ & $85 \%$ & 0.52 & $<0.001$ \\
\hline Right SM-IB & $96 \%$ & $100 \%$ & 0.89 & $<0.001$ \\
\hline Right IM-IB & $89 \%$ & $90 \%$ & 0.75 & $<0.001$ \\
\hline Left SM-AC & $81 \%$ & $85 \%$ & 0.56 & $<0.001$ \\
\hline Left SM-IB & $100 \%$ & $93 \%$ & 0.90 & $<0.001$ \\
\hline Left IM-IB & $95 \%$ & $83 \%$ & 0.78 & $<0.001$ \\
\hline
\end{tabular}

\section{DISCUSSION}

For a long time, mandibles were used to detect the sex of a person as they show a sexual difference in morphology. Also, there are high risks from the difference in the operators' skill. So, there is a need for many morphometric measures to be used as a standard for sex determination with other features. Many studies have reported that the skeletal criteria differ between populations, so there is a demand to put standards for the different populations (Suazo et al., 2008 and Saini, 2013).

The present study included 150 adult subjects (75 males and 75 females). Their ages ranged from 25 to 50 years. This age group was selected as the sex can be identified accurately from mandible after puberty. Because the mandibular growth process normally ends between 22 and 25 years of age, which is influenced by the complete eruption of the third molar tooth, which ends at the age of 25 in most populations. However, it may also be influenced by nutrition and socioeconomic status. While above 50 years of age, the loss of teeth is higher, affecting the mandible size. This, in addition to the effect of hormonal changes in menopausal females (Francesquini et al., 2007).

(A) Ramus measurements:-

In the present study, it was no statistical difference in the mean values of both left and right sides regarding Max.R.Br and Min.R.Br. in both females and males.

The current results agree with results reported by Noha \& Dina (2015) that used panoramic radiography to determine sex from the mandible and found that it was no significant difference found between the left and right sides regarding the Max.R.Br and Min.R.Br in males and females.

The present work showed a significant statistical increase in the mean values of both left and right, Max.R.Br in males compared to females. However, it was no detected statistical difference in the means of both left and right Min.R.Br between males and females.

In harmony with the present results, Sairam et al. (2016) reported that the mean values of male left and right Max.R.Br were higher than the female ones when used digital panoramic radiographs to determine sexual dimorphism.

While in contrast to the present work by using digital panoramic radiography, Ajit et al. (2016) and Tejavathi et al. (2017) found that the means of both left and right Max.R.Br were not differing statistically among males and females in the Indian population. This could be explained by differences in nutritional, geographic, and racial features (Patil et al., 2005).

The current findings were also in harmony with the findings reported by Altaf et al. (2019). They also detected by using orthopantomograms that both left and right Min.R.Br were not differing statistically among males and females in the Indian population.

In the present study, no significant statistical difference was determined 
between the mean values of both right and left sides regarding Condylar.R.Ht. and Coronoid.R.Ht. in males and females.

In harmony with the present work, Alves and Deana (2019) conducted a study to predict sex from macerated mandibles of Brazilian adults using metrical analysis and found no statistical difference in the mean values of the left and right regarding Condylar.R.Ht. and Coronoid.R.Ht. in both males and females.

While in contrast to the present result Amin (2018) demonstrated that among all mandibular linear measures, there was a significant difference in both left and right sides regarding Condylar.R.Ht. and Coronoid.R.Ht. in males and females with higher mean values in the right side compared to the left side in cone-beam computed tomography images and it was suggested that this difference possibly because of using the right side much more than the left side, with more contraction of mastication muscle as mastication temporalis, which is attached to the coronoid process.

It was a highly significant statistical increase in the right and left Condylar.R.Ht in males compared with females between male and female participants. Also, there was a highly significant statistical increase in the mean values of the left and right Coronoid.R.Ht in males compared to females.

The present work matched with a study by Neeru et al. (2018), who used panoramic radiography to compare sex and founded that males had greater mean values of both left and right Condylar.R.Ht and Coronoid.R.Ht in males as compared with females.

Similarly, Indira (2012) and Noha and Dina (2015), who used digital panoramic imaging, also found that the length of the left and right Condylar.R.Ht and Coronoid.R.Ht was more in males as compared to females with a highly significant difference.

In contrast to the present work, De Oliveira et al. (2015) assessed sexual dimorphism and age from analysis of the Condylar.R.Ht and Coronoid.R.Ht in lateral cephalometric radiographs. They reported that this measurement was reliable only for estimating the individual's age in the Brazilian population but presented no difference between sexes. This could explain the body's differences and development in different populations in males and females (Humphrey et al., 1999).

Mental foramen (M.F.) parameters: -

The present work was carried out in detail on Type II MF. Because the borders of this type can be traced, various markings can record various measurements. In the case of other types, i.e., Type I continuous and Type III diffuse, the M.F. margins cannot be visualized and therefore were not included in the study.

Many studies were performed using the M.F. position, and the results were documented. The vertical distance from the M.F. to the mandible's basal bone persists without change all over life. This part's fixedness may be attributed to high resistance against the alveolar process's resorption above the foramen (Guler et al., 2005). Due to the M.F. position's stability during life, it was chosen as a reference parameter in the present work.

The present work found no statistical difference in the mean values of both left and right sides regarding SM-AC, SM-IB, and IM-IB in males and females.

In harmony with the present work, Abha et al. (2019) found no statistical difference between both left and right sides regarding mental foramen parameters in males and females using panoramic radiography.

In contrast to the present work, Subash et al. (2019) used cone-beam computed tomography to determine sexual dimorphism by mental foramen analysis among the south Indian population and reported a significant statistical difference between right and left sides considering 
SM-IB and IM-IB in both males and females with higher values in the right side, and this was not in agreement with several researches by Mahima (2009) and Chandra et al. (2013) who found no significant variation between right and left sides of M.F. in panoramic radiography. He suggested that this difference in the results may be due to variations in population and radiographic techniques.

In the present study, a comparison between male and female groups showed that the male group had statistically significantly higher values for both rights and left SM-AC, SM-IB, and IM-IB than females.

The present results were in accordance with the results obtained by Abha et al. (2019), who used panoramic radiography to differentiate sex among the West Bengal population using mental foramen relations and reported that males had higher mean values as compared to females with a highly significant difference regarding both right and left SM-AC, SM-IB, and IM-IB.

Similarly, Thomas et al. (2014) and Burak et al. (2018) applied a mandible radiographic study to determine sex. They found that SM-AC, SM-IB, and IM-IB exhibit high sexual dimorphism with higher values in the male group.

The present work showed similar results obtained by Sairam et al. (2016), who used digital panoramic radiograph to determine sex from mandibular measurements and found that the SM-AC and SM-IB had higher values for males in comparison with females with the high significant statistical difference among Indian population.

The M.F. site's variance can be attributed to the variability of craniofacial skeletons' growth and development that depend on the sex hormones and local factors like muscles of mastication and mastication forces. As women have lesser developed muscles and weaker mastication force than men, so they have lesser deposited bone along the basal bone of the mandible (Jayam et al., 2015).

The variability between research can be since researchers work on variant sample sizes, instruments, inclusion criteria, positions or reference points, or variable analysis methods. Additionally, variability may be due to other factors, like the difference in group ancestry, including height, skeleton size, and environmental factors in different age and sex groups, in addition to the presence or absence of teeth (Sharan and Madjar, 2008).

In the current study, the benchmark scale was used to assess the percentage of the tested measurements' correct prediction of sex. The scale revealed that among all mandibular ramus measurements, the right and left Condylar.R. Ht were the best discriminate variables between genders with an overall accuracy of $97 \%$ in males and $100 \%$ in females. In comparison, the least predictor for sexual dimorphism was the Min.R. Br with an overall accuracy of $55 \%$ in males and $59 \%$ in females for the right side and $60 \%$ in males and $52 \%$ in females for the left side.

The present results matched with Indira et al. (2012) and Altaf et al. (2019), who used digital panoramic radiography to determine sex and concluded that among all mandibular parameters, the highest sexual dimorphism was seen with Condylar.R.Ht as the overall prediction rate was $87 \%$ in males and $90 \%$ in females with least sexual dimorphism was seen with Min.R.Br.

Similarly, Bhagwatkar et al. (2016) measured all the parameters in mandibles of 100 Indian subjects by using digital orhopantomograph and concluded that mandibular ramus height, specifically Condylar.R.Ht was the most significant with the best-predicting accuracy rate of $85 \%$.

In agreement with the current results, Aspalilah et al. (2018) applied a retrospective study by using postmortem computed tomography scans of a sample of the Malaysian population and 
demonstrated that all mandibular parameters were found to be more generous in male mandibles than in female one with an overall accuracy of $78.5 \%$. However, by stepwise discriminant function analysis, from nine parameters, Condylar.R.Ht and Coronoid.R.Ht were the best parameters for predicting sex correctly.

The present work demonstrated that among all mental foramen relations, the SM-IB was the best predictor of sex between male and female groups with an overall accuracy of $96 \%$ in males and $100 \%$ in females for the right side and $100 \%$ in males and $93 \%$ in females for the left side. On the other hand, the least discriminant variable was the SM-AC with an overall accuracy rate of $79 \%$ in males and $85 \%$ in females for the right side and $81 \%$ in males and $85 \%$ in females for the left side.

The present results matched with Sairam et al. (2016), who concluded that among all linear measurements of mental and mandibular foramina, the SM-IB was the best measurement tested in the prediction of sex in digital panoramic radiographs with an overall accuracy of $85 \%$ in males and $90 \%$ in females.

In harmony with the current results, Girish et al. (2016), who established a retrospective study on the Indian population using 100 panoramic radiography for subjects of known gender, concluded that among all mental foramen parameters, the SM-IB and IM-IB exhibited the best predictors of sex.

In contrast to the present work, Nimi et al. (2017) and Sandeepa et al. (2017) used panoramic imaging. They reported that Min.R. Br and Max.R. Br on both sides were the best measurements in predicting sex among Indian and Saudi Arabian populations. This difference may be postulated to racial variety.

\section{Conclusion}

The present study revealed no significant statistical difference between right and left sides regarding all measured mandibular and mental foramen parameters in both males and females. A significant statistical increase in the mean values of the left and right, Max.R.Br was found in males compared to females. Simultaneously, no significant statistical difference was found in the mean values of left and right Min.R.Br between males and females.

A significant statistical increase in the mean values of the left and right Condylar.R.Ht and Coronoid.R.Ht was found in males compared to females. A significant statistical increase in the mean values of the left and right SM-AC, SMIB, and IM-IB was found in males compared with females. Finally, the mean values of left and right Condylar.R.Ht and SM-IB were the correct predictors of both genders.

\section{RECOMMENDATIONS}

- It is recommended to use another type of radiation as cone-beam computed tomography (CBCT) or three-dimensional computed tomography (3D-CT). These types will be more accurate than panoramic radiographs in detecting the different landmarks of the measured parameters.

- It is better to use a larger sample size than that was chosen in the present work to have the availability to determine a specific range and cut off point to the different parameters.

- It is recommended to select a broader range for the age group to correlate between different age groups and the best parameter in determining sex in each age group.

\section{REFERENCES}

Abha, R.; Varsha, K.; Deepak, K. and Rajeshwari G. A. (2019): Morphometric assessment of mental foramen for gender prediction using panoramic radiographs in the West Bengal population - A retrospective digital study. Journal of Advanced Clinical \& Research Insights, 6:63-66. 
Ahmed, A.G.; Gataa, I.S.; Fateh, S.M. and Mohammed, G.N. (2015): CT scan images analysis of maxillary sinus dimensions as a forensic tool for sexual and racial detection in a sample of Kurdish sample. European Scientific Journal, 11:272-281.

Ajit, D.; Jonnala, M.; Pavan. K.Y. and Begum, M. R. (2016): Radiographic evaluation of mandibular ramus for gender estimation: Retrospective study. Journal of Forensic Dental Sciences, 8(2):74-78.

Al-Shamout, R.; Ammoush, M.; Alrbata, R. and Al-Habahbah, A. (2012): Age and gender differences in gonial angle, ramus height and bigonial width in dentate subjects. Pakistan Oral \& Dental Journal, 32:81-87.

Altaf, H.C.; Shazia, M. and Bashir, A.W. (2019): Radiographic evaluation of sexual dimorphism in mandibular ramus: A digital orthopantomography study. International Journal of Applied Dental Sciences, 5(1):163-166.

Alves, N. and Deana, N.F. (2019): Sex prediction from metrical analysis of macerated mandibles of Brazilian adults. International Journal of Morphology, 37(4):1375-1381.

Amin W.M. (2018): Osteometric assessment of various mandibular morphological traits for sexual dimorphism in Jordanians by discriminant function analysis. International Journal of Morphology, 36(2):642-650.

Andreas, B.; Konstantina, A. and Maria-Eleni, C. (2019): Estimating sex using discriminant analysis of mandibular measurements from a modern Greek sample. Egyptian Journal of Forensic Sciences, 9:25:112.

Aspalilah, A.; Abdel-Nasser, I.; Siti, N.A.; Mohamed, S.S.; Srijit, D.; Nurliza, A.; Helmee, M.N.; Iman, Y.L. and Faridah, M.N. (2018): Anthropometric analysis of mandible: an important step for sex determination. Clinical Therapeutics Journal, 169(5):e217-223.

Bhagwatkar, T.; Thakur, M.; Palve, D.; Bhondey, A.; Dhengar, Y. and Chaturvedi S. (2016): Sex determination by using mandibular ramus - A forensic study. Journal of Advanced Medical and Dental Sciences Research, 4:1-6.

Burak, A.; Derya, I.; Fusun, Y. and Faruk, A. (2018): Evaluation of mandibular anatomical formation for gender determination in Turkish population. Balkan Journal of Dental Medicine, 22:133-137.

Chandra, A.; Singh, A.; Badni, M.; Jaiswal, R. and Agnihotri, A. (2013): Determination of sex by radiographic analysis of mental foramen in North Indian population. Journal of Forensic Dental Sciences, 5:5255.

De Oliveira, F.T.; Soares, M.Q.; Sarmento, V.A.; Rubira, C.M.; Lauris, J.R. and Rubira-Bullen, I. R. (2015): Mandibular ramus length as an indicator of chronological age and sex. International Journal of Legal Medicine, 129(1):195-201.

Francesquini, J.; Francesquini, M.; De La Cruz, B.; Pereira, S.; Ambrosano, G.; Barbosa, C.; Daruge Júnior, E.A.A. Del Bel Cury, A. and Daruge, E. (2007): Identification of sex using cranial base measurements. The Journal of Forensic Odonto-Stomatology, 25(1):7-11.

Franklin, D.; Higgins, P.; Oxnard, C. and Dadour, I. (2008): Discriminant function sexing of the mandible of Indigenous South Africans. Forensic Science International Journal, 179(1):84e1-84 e5.

Girish, S.; Ashwinirani, S.; Vineetha, C.; Renuka, P. and Ajay, N.(2016): Gender determination by radiographic analysis of mental foramen in the Maharashtra population of India. 
Journal of Forensic Dental Science, 8(3):176-180.

Guler, A.; Sumer, M.; Sumer, P. and Bicer, I. (2005): The evaluation of vertical heights of maxillary and mandibular bones and the location of anatomic landmarks in panoramic radiographs of edentulous patients for implant dentistry. Journal of Oral Rehabilitation, 32:741-746.

Medico-Legal Update Humphrey, L.T.; Dean, M.C. and Stringer, C.B. (1999): Morphological variation in modern human mandibles. Journal of Anatomy, 195:491-513.

Indira, A.P.; Markande, A. and David, M.P. (2012): Mandibular ramus an indicator for sex determination - A digital radiographic study. Forensic Dental Sciences Journal, 4:58-62.

Jambunath, U.; Govindraju, P.; Balaji, P.; Poornima, C. and Latha, S. (2016): Sex determination by using mandibular ramus and gonial angle $-\mathrm{a}$ preliminary comparative study. International Journal of Contemporary Medical Research, 3(11):77-83.

Jayam, R.; Annigeri, R.; Rao, B.; Gadiputi, S. and Gadiputi, D. (2015): Panoramic study of mandibular basal bone height. Journal of Orofacial Sciences, 7:7-10.

Kartheeki, B.; Abhishek, B.; Singh, A.; Nayyar, Y.; Udaya, A.; Sindhu, N. and Lakshmana, U. (2017): Accuracy of mandibular rami measurements in prediction of sex. Archives of Medicine and Health Sciences, 5(1):53-60.

Kiran, C.S.; Ramaswamy, P. and Khaitan, T. (2014): Frontal sinus index - new tool for sex determination. Journal of Forensic Radiology and Imaging, 2:25-30.

Kumar, M.P. and Lokanadham, S. (2013): Sex determination and morphometric parameters of human mandible. International Journal of Research in Medical Sciences, 1:9396.
Landis J.R. and Koch G.G. (1977): The measurement of observer agreement for categorical data. International Biometric Society, 33(1):159-174.

Lopez-Capp, T.T.; Rynn, C.; Wilkinson, C.; de Paiva, L.A.; Michel Crosato, E. and Biazevic, M.G. (2018): Discriminant analysis of mandibular measurements for the estimation of sex in a modern Brazilian sample. International Journal of Legal Medicine, 132(3):843-851.

Mahima, V.G. (2009): Mental foramen for gender determination: A panoramic radiographic study. Medico-legal Update, 9 (2):33- 35.

Neeru, P.; Altaf, H. and Nahida, D. (2018): Mandibular ramus: an indicator for gender determination - A digital radiographic study. International Journal of Scientific Study, 6(7):42-45.

Nimi, S.; Laxmikanth, C.; Prashanth, S.; Veena, K.; Rachana, V. and Prabhu, B. (2017): Gender determination in panoramic radiographs, utilizing mandibular ramus parameters: a cross-sectional study. Journal of Dental Research and Review, 4(2):32-35.

Noha, S. and Dina, M. (2015): Mandibular ramus and gonial angle measurements as predictors of sex and age in an Egyptian population sample: A digital panoramic study. Journal of Forensic Research, 6(5):1-7.

Osunwoke, E.A.; Amah-Tariah, F.S.; Obia, O.; Ekere, I.M.; and Ede, O. (2011): Sexual dimorphism in facial dimensions of the bini's of southsouthern Nigeria. Asian Journal of Medical Sciences, 3:71-73.

Patil, K. and Mody, R.N. (2005): Determination of sex by discriminant function analysis and stature by regression analysis: a lateral cephalometric study. Forensic Science International Journal, 147:175-180.

Saini, V. (2013): Metric study of fragmentary mandibles in a North 
Indian population. Bulletin of the International Association of Paleodontology, 7:157-162.

Sairam, V.; Geethamalika, M.; Praveen B.; Kumar, G.; Naresh, G. and Raju, P. (2016): Determination of sexual dimorphism in humans by measurements of mandible on digital panoramic radiograph. Clinical Dentistry Journal, 7(4):434-439.

Sandeepa, N.C.; Atheer, A.G.; Wala, A.A.; Yosra, M.M.; Eman, K.A. and Afnan, H.A. (2017): Mandibular indices for gender prediction: A retrospective radiographic study in Saudi population. International Journal of Dentistry and Oral Health, 3(9):1-7.

Sharan, A. and Madjar, D. (2008): Maxillary sinus pneumatization following extractions: A radiographic study. International Journal of Oral and Maxillofacial Implants, 23:48-56.

Sharma, S.; Jehan, M. and Kumar, A. (2014): Measurements of maxillary sinus volume and dimensions by computed tomography scan for gender determination. Journal of the Anatomical Society of India, 63:3642.

Singh, R.; Mishra, S.R.; Passey, J.; Kumar, P.; Singh, S.; Sinha, P. and Gupta, S. (2015): Sexual dimorphism in adult human mandible of North Indian origin. Forensic Medicine and Anatomy Research, 3:82-88.
Suazo, G.I.; Pedro, S.V.; Schilling, Q.N. (2008): Ortopantomographic blind test of mandibular ramus flexure as a morphological indicator of sex in Chilean young adults. International Journal of Morphology, 26(1):89-92.

Subash, T.S.; Balaraj, B.M. and Hema, C. (2019): Determination of sex by cone-beam computed tomography analysis of mental foramen in South Indian population. International Journal of Forensic Odontology, 4(1):21-26.

Tejavathi, N.; Leena, J.; Sita, G.; Noori, G. and Haritma, N. (2017): Sex determination by using mandibular ramus: A digital radiographic study. Journal of Medicine, Radiology, Pathology \& Surgery, 4(4):5-8.

Thomas, C.J.; Madsen, D. and Whittle, C. (2014): A radiologic survey of the edentulous mandible relevant to forensic dentistry. Lebanon Journal of Dental Medicine, 3:15-20.

Tsorovas, G. and Karsten, A. (2010): A comparison of hand tracing and cephalometric analysis computer programs with and without advanced features _ accuracy and time demands. European Journal of Orthodontics, 32:721-728.

Vijay, K.A. and Jigna, S.S. (2018): Mental Foramen: A predictor of age and gender and guide for various procedures. Journal of Forensic Science and Medicine, 4(2):76-84. 


\section{تحديا الجنس باستخدام عدة قياسات لقرع القك السفلي وعلامات الثقبة الأقنية

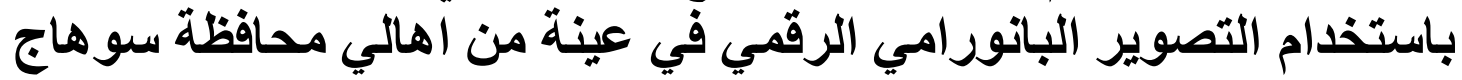

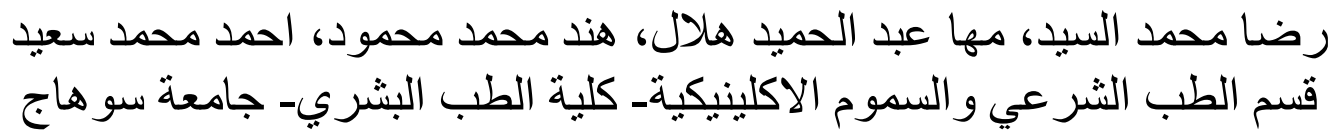

يعتبر التعرف على رفات الهياكل العظمية البشرية من الجثث المتحللة والمتضررة خلال الكوارث

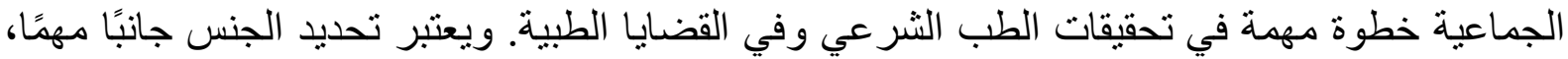
يليه تحديد العمر. ويمكن تحديد الجنس من عظام الحوض والجمجمة مع القك السفلي. حيث يعتبر الفك

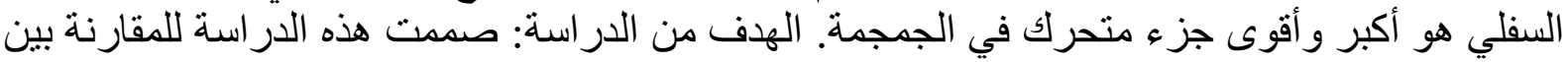
قياسات فرع الفك السفلي و علاقات الثقبة الذقنية على كلا الجانبين لتحديد الجنس من خلاءل التهن التصوير

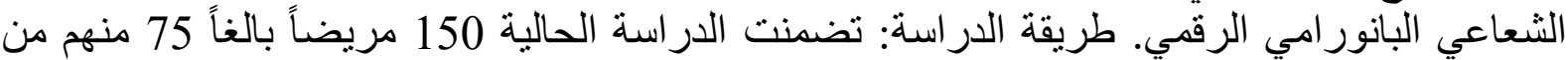

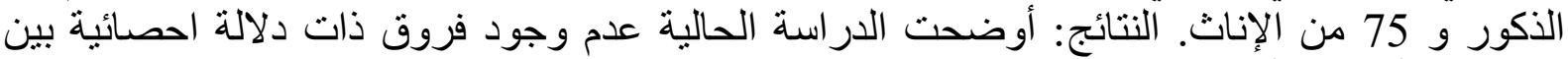

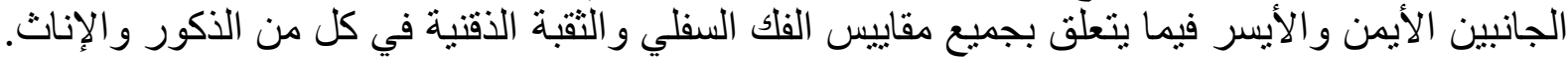

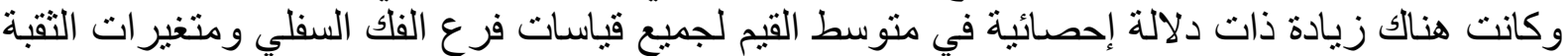

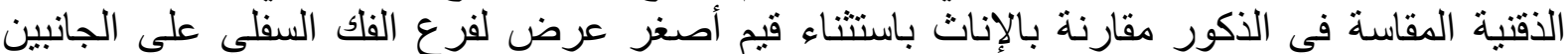

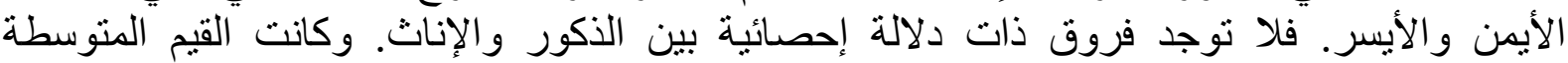
Condylar. R. Height الجنس عند الذكور و الإناث. 